\title{
Geospatial and Temporal Clustering of Folic Acid- Sensitive Congenital Defects in Villa Clara Province, Cuba
}

\author{
Noel Taboada Lugo ${ }^{1 *}$, Manuela Herrera Martínez², Geni Hernández González ${ }^{3}$ and Hartley \\ Ledesma Hernández ${ }^{4}$ \\ ${ }^{1}$ Master of Sciences, Medical Doctor, Terminal Professional Degree in Clinical Genetics, Department of Medical Genetics, \\ Principal and Adjunct Professor of Medical Genetics at the Villa Clara Medical University, Cuba
}

${ }^{2}$ PhD, Medical Doctor, Terminal Professional Degree in Clinical Genetics, Biomedical Research Unit, Titular Professor of Medical Genetics at the Villa Clara Medical University, Cuba

${ }^{3}$ Medical Doctor, Terminal Professional Degree in Biostatistics. Health Vigilance Department, Villa Clara Health Provincial Direction, Cuba

${ }^{4}$ Bachelor's degree in Technical and Professional Teaching, Health Vigilance Department, Villa Clara Health Provincial Direction, Cuba

*Corresponding author: Noel Taboada Lugo, Master of Sciences, Medical Doctor, Terminal Professional Degree in Clinical Genetics,

Department of Medical Genetics, Principal and Adjunct Professor of Medical Genetics at the Villa Clara Medical University, Cuba

\section{ARTICLE INFO}

Received: 蔧 August 06, 2020

Published: 幽 August 28, 2020

Citation: Noel Taboada L, Manuela Herrera M, Geni Hernández G and Hartley Ledesma H. Geospatial and Temporal Clustering of Folic Acid- Sensitive Congenital Defects in Villa Clara Province, Cuba. Biomed J Sci \& Tech Res 29(5)-2020. BJSTR. MS.ID.004865.

Keywords: Birth Defects; Birth Prevalence; Geospatial Cluster; Cluster Analysis; Spatiotemporal Analysis

Abbreviations: BDs: Birth Defects; FA: Folic Acid; NTDs: Neural Tube Defects; CTDs: Conotruncal Heart Defects; RR: Relative Risk; CHDs: Congenital Heart Diseases

\section{ABSTRACT}

Introduction: Geospatial and temporal clusters are defined as the occurrence of an unusual number of cases higher than expected in a given geographical area in a certain period of time.

Objectives: to determine the birth prevalence rate of birth defects sensitive to folic acid deficiency and to identify, describe, and characterize potential geospatial and temporal clusters of these birth defects in Villa Clara province, Cuba.

Methods: The cases were ascertained from 46007 total births, record of 267 cases with prenatal or postnatal diagnosis of five folic acid- sensitive selected birth defect were acquired based on hospital registers and community based registers too. Spatial scan statistic was used to determine areas of the province with spatial and temporal clusters for the birth defects sensitive to folic acid deficiency under study.

Results: The overall adjusted birth prevalence was 58.0 per 10000 births. The highest prevalence rate occurred in conotroncal heart defects, followed by Down syndrome and neural tube defects, meanwhile orofacial clefts and gastroschisis shown the lowest prevalence rates. Overall, the prevalence of folic acid- sensitive congenital defects under study declined over the six years of the study. A primary spatial and spatio-temporal cluster for the birth defects under study was identified in two neighboring municipalities and secondary spatial clusters were identified in another three municipalities.

Conclusion: Identification of birth defects geospatial clusters must be faced recognizing that such challenge is in fact an opportunity to achieve a better knowledge of causes of these birth defects. 


\section{Introduction}

A congenital defect geospatial and temporal cluster can be defined as the occurrence of an unusual number of birth defects (BDs) cases higher than expected in a given geographical area in a certain period of time. Many BDs can be prevented, and identification of clusters may provide an opportunity for targeted interventions designed to prevent specific BDs. Examining the geographic distribution of birth defects can also be useful in exploratory etiologic research [1]. The pattern and prevalence of BDs may vary over time or with geographical location, reflecting a complex interaction of known and unknown genetic and environmental factors. The most established environmental factor is dietary folate; lower levels of folic acid (FA) are observed in mothers with some kinds of BDs pregnancy, and periconceptional FA supplementation can reduce the risk of different BDS [1-3]. Among FA- sensitive congenital defects included in the literature are Neural tube defects (NTDs), orofacial clefts, gastroschisis and conotruncal heart defects (CTDs), reductive limb defects, congenital urinary tract anomalies and Down syndrome, as chromosomal abnormality [2,4-7].

The services of medical genetics in Cuba are integrated under the National Program for diagnosis, management and prevention of genetic diseases and BDs. This program started in the 1980s. The services are implemented through a community genetics network that currently has 168 municipal genetics services, 15 provincial services and the National Center of Medical Genetics in Havana city [8]. Since 1985, the Cuban Registry of Congenital Malformations (RECUMAC, for its name in Spanish) has been used as a research program for BDs that allows establishing a system of clinical and epidemiological surveillance of them in the hospital births. This record includes all live births or still births weighing 500 grams or more with one or more major BDs upon physical exam during the first 24 hours after birth. The information in this registry continues to grow, covering up to $96 \%$ of the total births in the country [8]. Villa Clara province is located in the central region of the island of Cuba, with a superficial extension of 8 411, 81 square kilometers, occupying the fourth place among the fifteen Cuban provinces and representing the $7.6 \%$ of the total area of the country.

It has 13 municipalities with a population of 780749 inhabitants, and there are four maternity hospitals for a female population of 39070 persons, 174075 of them are in reproductive age. From January 2013 to December 2018 there was 46007 birth (45 692 live births and 315 stillbirths) in Villa Clara [9]. No studies associating folic acid- sensitive BDs and their geographical distributions in Cuba were found in the literature. Therefore, the main goals of this study were to determine the birth prevalence rate of these BDs and to identify, describe, and characterize potential geospatial and temporal clusters of BDs sensitive to folic acid deficiency in Villa Clara province, Cuba.

\section{Methods}

This observational descriptive study was performed with data obtained by RECUMAC and obtained from the Cuban Prenatal Register of Congenital Malformations (RECUPREMAC, for its name in Spanish), a multicenter, hospital-based and population-based registers of major birth defects from January 2013 to December 2018. Data of RECUMAC was obtained from all Maternity Hospital of the Villa Clara Province and from the Municipal Centers of Medical Genetics of the 13 municipalities of this province, where all new born are examined at month and at three month of life. On the other hand, data of RECUPREMAC was obtained from the Villa Clara Provincial Department of Medical Genetics. These registries cover live births, fetal deaths from 20 weeks gestational age and terminations of pregnancy for fetal anomaly. Congenital defects were coded according to the Tenth Revision of the International Statistical Classification of Diseases and Related Health Problems for Diagnoses (ICD-10).

The following FA- sensitive BDs were included: NTDs, orofacial clefts, gastroschisis, CTDs and Down syndrome as chromosomal abnormality related to folic acid maternal deficiency. Only isolated cases of BDs were considered in the study. We excluded from the analysis all syndromic cause of BDs with exception of Down syndrome. In all cases of congenital heart defects diagnostic procedures were performed (i.e., prenatal or transthoracic postnatal echocardiogram) for definitive diagnosis of CTDs. All cases of trisomy 21 were cytogenetically diagnosed (pre or postnatal karyotyping studies) and cases with chromosomal mosaicism or translocations were excluded. Adjusted prevalence rate at birth of BDs was calculated by dividing the numerator (registered cases of live birth, stillbirth or elective pregnancy terminations with any of the selected BDs from 2013 to 2018) by the denominator (total number of live births and stillbirth in the same period). The prevalence rate was expressed as the number of cases per 10000 total births.

The prevalence was estimated for each analysis spatial unit (municipality) based on the total number of births occurring in the municipality during the period. The considered temporal unit was the year. We first assessed temporal trends in the birth prevalence of all studied BDs and afterwards by specific types. Data were stratified according to geographic area of maternal residence (13 municipalities) and year (6 strata from 2013-2018), resulting in 78 strata. To perform the spatial and spatiotemporal BDs cluster detection, the Spatial Scan Statistics was used, with the assumption that the number of cases for the FA- sensitive congenital defects under study in each area follows a Poisson distribution. Open access SaTScan 7.0.1 software was used for this analysis, employing the scan technique to identify those areas with high rates, which can include different groups of neighboring spatial units (municipalities). This method permits us to identify 
high risk groups in the spatial units associated with FA- sensitive congenital defects under study. The expected number of cases in each area is calculated as: $\mathrm{E}[\mathrm{c}]=\mathrm{p} \times \mathrm{C} / \mathrm{P}$

Where $\mathrm{c}$ is the observed number of BDs, $\mathrm{p}$ is the population of reference (live births, stillbirths and elective pregnancy terminations) in each municipality, whereas $\mathrm{C}$ and $\mathrm{P}$ are the total number of BDs and births, respectively [10]. A relative risk (RR) for each spatial unit is calculated by dividing the observed number of BDs by the expected number of them, as follows:

Where $\mathrm{c}$ is the observed number of BDs within the cluster, $\mathrm{E}$ is the expected number of cases, and $C$ is the total number of cases [11]. To identify these spatial clusters, the likelihood ratio test is used, which checks whether the observed number of cases in a spatial unit exceeds the expected number of cases. The area with the maximum value of likelihood was considered a primary cluster. The critical value for significance was set at $p<0.05$. To identify the characteristics of the spatial distribution of the studied BDs, we used tendency analysis techniques and evaluations of the spatial association and concentration. In the spatial tendency analysis, the clusters of prevalence per municipality are represented by using colours degradation (from dark red to pale red and pink). MapInfo 7.0 software was used to draw the maps on spatial distribution. This study is based on an analysis of existing registered data and all identifier information was opportunely removed, according the ethical issues on human investigations. It was approved by the ethical committee of the Biomedical Research Unit of the Villa Clara Medical University.

\section{Results}

Between 2013 and 2018, the RECUMAC and RECUPREMAC database in Villa Clara recorded 267 cases of the folic acid- sensitive congenital defects included in this study. Of them five were identified among stillbirths (1.9\%), 108 in live births (40.4\%), and
$154(57.7 \%)$ were elective termination of pregnancy. The overall adjusted birth prevalence was 58.0 per 10000 births as it's shown in Table 1.

Table 1: Adjusted prevalence rate of folic acid- sensitive congenital defects in Villa Clara province, Cuba. Years 2013 to 2018.

\begin{tabular}{|c|c|c|c|}
\hline $\begin{array}{c}\text { Congenital } \\
\text { defects }\end{array}$ & Cases & Prevalence & $\begin{array}{c}\text { ICD-10 Codes } \\
\text { and Subcodes }\end{array}$ \\
\hline $\begin{array}{c}\text { Conotruncal } \\
\text { heart defects }\end{array}$ & 80 & 17.4 & $\begin{array}{c}\text { Q20.0, Q20.1, } \\
\text { Q20.3, Q20.4, } \\
\text { Q21.3, Q22.0, } \\
\text { Q25.2 }\end{array}$ \\
\hline Down syndrome & 61 & 13.3 & Q90 \\
\hline $\begin{array}{c}\text { Neural tube } \\
\text { defects }\end{array}$ & 59 & 12.6 & Q00, Q01, Q05, \\
\hline Orofacial clefts & 36 & 7.8 & Q35, Q36, Q37 \\
\hline Gastroschisis & 31 & 6.7 & Q79.3 \\
\hline Total & 267 & 58.0 & - \\
\hline
\end{tabular}

The highest prevalence rate occurred in CTDs, followed by Down syndrome and NTDs, meanwhile orofacial clefts and gastroschisis shown the lowest prevalence rates. CTDs, Down syndrome and NTDs accounted for the three quarter parts of the cases $(200 / 267,75.0 \%)$. Overall, the prevalence of FA- sensitive congenital defects under study declined over the six years of the study, with prevalence rates from 68.4 per 10000 total births in 2013 to 54.1 per 10000 total births in 2018. Rates of most BDs subtypes decreasing significantly per annum (Gastroschisis with prevalence from 11.4 per 10000 total births in 2013 to 6.7 per 10 000 total births in 2018, Orofacial clefts from 15.2 per 10000 total births in 2013 to 2.7 per 10000 total births in 2018, and Down syndrome from 17.7 per 10000 total births in 2013 to 9.4 per 10 000 total births. On the other hand, rates of NTDs and conotroncal heart defects increased slightly from 17.7 and 15.2 per 10000 total births in 2013 to 18.8 and 17.4 per 10000 total births in 2018, respectively (Figure 1).

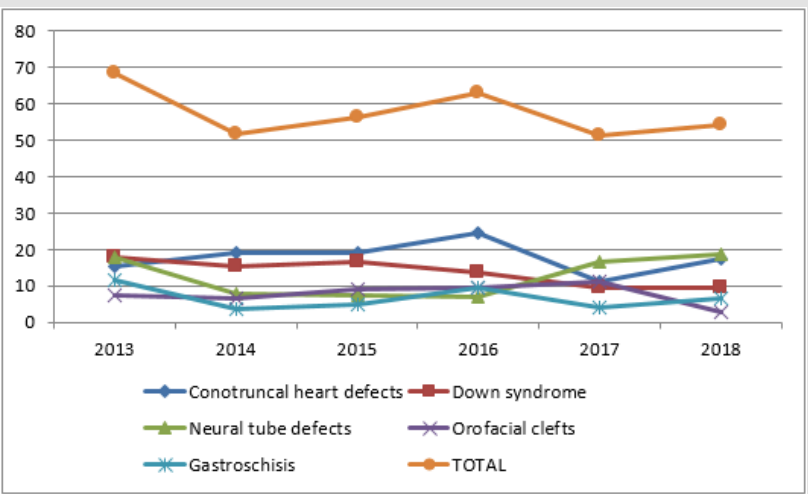

Figure 1: Temporal trends in folic acid- sensitive congenital defects as total group and by type in Villa Clara province, Cuba. Years 2013 to 2018. 
Figure 2 shows a primary spatial cluster for the BDs under study in two neighboring municipalities (Corralillo and Quemado de Güines) where the observed number of cases in the period of time was 23 and the expected cases were 14.6 (Table 2). Secondary spatial clusters were identified in another three municipalities, although none were statistically significant. The population of Corralillo and Quemado de Güines (primary cluster) has a risk of 1.63 , whereas for the population of Placetas, Manicaragua and Encrucijada the risk is $1.44,1.25$ and 1.36 , respectively. The most frequent FA- sensitive congenital defects observed in the primary cluster were conotroncal heart defects (36.4\%) and orofacial clefts $(27.3 \%)$, meanwhile in the secondary cluster located in Placetas municipality the most prevalent BDs were the NTDs $(32.3 \%)$ and conotroncal heart defects (22.6\%). On the other hand, in Manicaragua municipality, Down syndrome (32.3\%) and gastroschisis (24.1\%) had the highest frequencies, and in the third secondary cluster identified in Encrucijada municipality, the most frequent BDs were conotroncal heart defects (38.5\%) and NTD (23.1\%) (Results not shown).

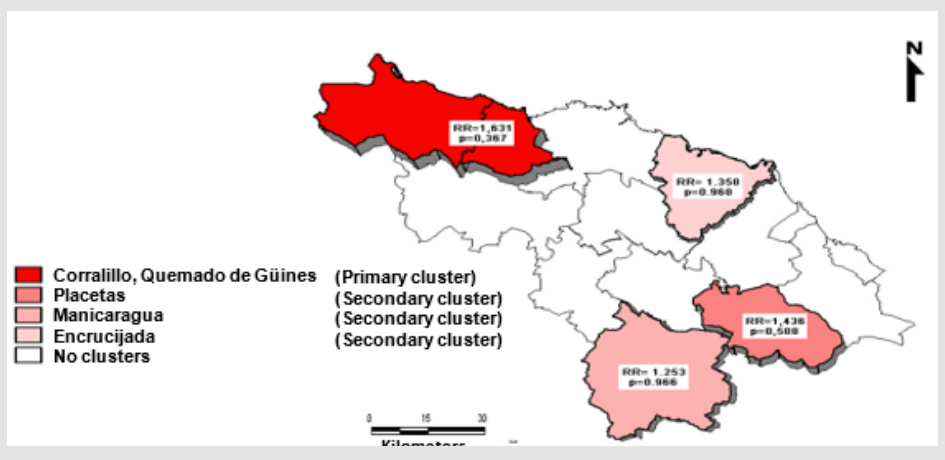

Figure 2: Geospatial clusters map for the studied folic acid- sensitive congenital defects for the period 2013-2018, Villa Clara province, Cuba.

Table 2: Spatial clusters for the studied folic acid- sensitive congenital defects in Villa Clara province, Cuba. Years $2013-2018$.

\begin{tabular}{|c|c|c|c|c|}
\hline \multirow{2}{*}{ Clusters } & Municipalities & Observed & Expected & Relative \\
Cases & Risk & 14.6 & 0.37 \\
\hline Primary & $\begin{array}{c}\text { Corralillo, Quemado de } \\
\text { Güines }\end{array}$ & 23 & 22.4 & 1.44 \\
\hline Secondary & Placetas & 31 & 23.7 & 1.25 \\
\hline Secondary & Manicaragua & 29 & 11.2 & 0.59 \\
\hline Secondary & Encrucijada & 15 & 0.97 \\
\hline
\end{tabular}

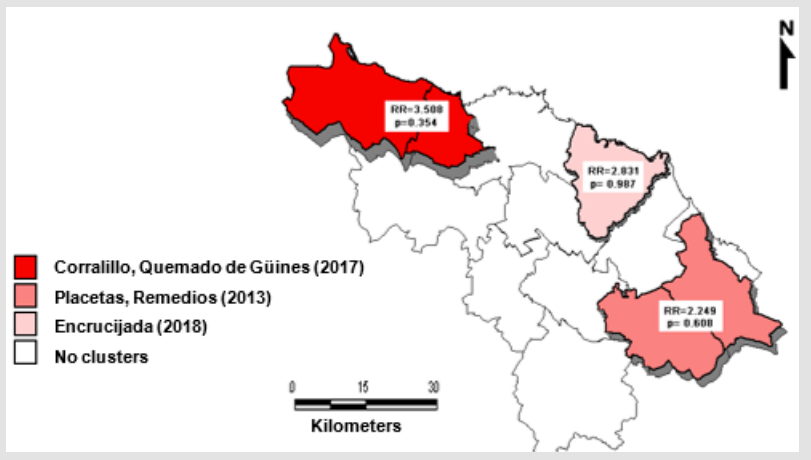

Figure 3: Spatio-temporal clusters map for the studied FA- sensitive congenital defects for the period 2013-2018, Villa Clara province, Cuba. 
A primary spatio- temporal cluster for the five under study BDs in the same neighboring municipalities of Corralillo and Quemado de Güines was found in the year 2017. Other secondary spatio- temporal clusters were identified in the years 2013 (in the neighboring municipalities of Placetas and Remedios) and in the year 2018 in the municipality of Encrucijada (Figure 3).

Table 3 provides results related to the spatio-temporal clusters, such as the municipalities making up the clusters and year, the expected and observed number of cases, the relative risk and the p-value.

Table 3: Spatio- temporal clusters for the folic acid- sensitive congenital defects under study in Villa Clara province, Cuba. Years 2013-2018.

\begin{tabular}{|c|c|c|c|c|c|c|}
\hline Clusters & Municipalities & Years & $\begin{array}{c}\text { Observed } \\
\text { Cases }\end{array}$ & $\begin{array}{c}\text { Expected } \\
\text { Cases }\end{array}$ & $\begin{array}{c}\text { Relative } \\
\text { Risk value }\end{array}$ & \multirow{2}{*}{6.47} \\
\hline Primary & $\begin{array}{c}\text { Corralillo, } \\
\text { Quemado d } \\
\text { Güines }\end{array}$ & 2017 & 8 & 1.4 & & \\
\hline Secondary & Placetas, Remedios & 2013 & 31 & 22.4 & 2.25 & 0.013 \\
\hline Secondary & Encrucijada & 2018 & 15 & 11.2 & 2.83 & 0.99 \\
\hline
\end{tabular}

\section{Discussion}

The prevalence of the FA- sensitive congenital defects under study vary widely across studies, most of them postulated that congenital heart defects are the most frequently occurring BDs in newborns and the most common type of structural malformation of the heart and lager blood vessels, affecting approximately $1 \%$ of newborns and account for approximately one-third of infant deaths associated with major BDs, of which CTDs are one of the most common cardiovascular defects [12]. Nevertheless, for Liao, et al. [13], NTDs have the highest incidence among all BDs. Globally, NTDs prevalence is estimated to be over 300000 new cases per annum, with over 40000 deaths and 2.3 million disability-adjusted life years. NTDs prevalence in Latin American countries varied from 0.2 to 9.6 per 1000 live births and was influenced by methods of ascertainment [14]. In the current study the prevalence rate for Down syndrome was slightly higher than the prevalence rate for NTDs.

The prevalence rate for Down syndrome in Villa Clara province (13.3 per 10000$)$ was higher than the prevalence reported in Korea (4.7 per 10000) and Japan (10.9 per 10000); however, other population-based studies had reported higher than this figure in Finland (31.0 per 10000) and France (27.3 per 10000). This syndrome can be diagnosed relatively easily prior to birth. Hence, it is likely that many fetuses with the syndrome might have aborted electively, and this may have contributed to the variable prevalence rates [15]. The temporal trends in the five studied FAsensitive congenital defects for the period 2013-2018 showed a declining pattern. This downward time trend could be explained by the increasing intake of FA because in the Villa Clara province a preventive program, designed to encourage preconceptual FA supplementation use in women of childbearing age, was implemented since middles of the year 2015.
Most significant decreasing was observed in orofacial clefts and Down syndrome. Isolated cleft lip with or without cleft palate and cleft palate only are two complex disorders within the non syndromic orofacial cleft spectrum, which is among the most common human BDS, affecting 135000 newborns worldwide each year, being the fourth most common BDS in the United States [16]. Non syndromic orofacial clefts are multifactorial BDs attributed to both environmental and genetic factors. It has been suggested that orofacial clefts are related to maternal exposure to environmental risk factors, including folate and vitamin deficiencies, during the first trimester of pregnancy $[4,17]$. Folate is essential for normal cell division and as intrauterine fetal growth involves a process of rapidly dividing cells, there is a consequent increased requirement for folate at this time. Folate, and the synthetic form folic acid, (FA) is thus vital for the early development process. It plays a major role in one-carbon metabolism in the synthesis of nucleotides and amino acids and in DNA methylation, epigenetic mechanism which is essential for chromatin dynamics and consequent gene expression $[4,6,18]$.

In vivo and in vitro FA deficiency has been associated with DNA hypomethylation, DNA strand break and abnormal or impaired chromosome segregation. James et al. [19] were the first to propose the hypothesis that altered DNA methylation patterns resulting from abnormal folate metabolism may increase DNA hypomethylation in centromeric and pericentromeric regions, thus increasing the risk of chromosome nondisjunction resulting in Down syndrome. Down syndrome due to trisomy of chromosome 21 is a result of a nondisjunction during maternal meiosis in the majority of cases. In our study this aneuploidy has a prevalence at birth adjusted of 13.3 per 10000 births. In the Villa Clara province Down syndrome occurs with a prevalence of one in 749 live births, according the prevalence reported in the literature (1: 700-800 live births) [20,21]. A 
decreasing prevalence trend of this aneuploidy, in the period of six years, was found in Villa Clara.

Likewise, the majority of countries showed a generalized decrease in the NTDs prevalence in time too, because of FA supplementation and fortification strategies [7,14,22]. Nevertheless, in the current study a declining tendency was interrupted in the last two years when a slight increase was observed. In the literature a number of cases are due to some cause other than alterations of methylation patterns. Well-established evidence shows that women, who are obese, have poorly controlled diabetes; take certain antiseizure medications or folate antimetabolites or are exposed to chemical elements, are at greater risk than are other women of having an infant with NTDs [13,23,24]. Differences in NTDs prevalence by country can also be explained by geographic variation. For example, higher NTDs prevalence in some areas of Brazil, Guatemala, Honduras and Mexico is consistent with higher levels of poverty, higher conception rates for younger mothers, and less access to health services and fortified staples. In contrast, the observed increase in Cuba's NTDs prevalence trend was most likely due to differential ascertainment: changes in inclusion criteria, increase in number of participating hospitals and inclusion of elective pregnancy terminations [10].

CTDs comprise a subgroup of congenital heart diseases (CHDs) that are malformations of cardiac outflow tracts and great arteries. These malformations share a common structural origin, being derived from cardiac neural crest cells and secondary heart field. CTDs account for approximately $20 \%$ to $30 \%$ of all CHDs and occur in 7 per 10000 live births [25,26]. In the Villa Clara province, the prevalence rate from 2013 to 2018 was quite higher (17. 4 per 10000 births), presumably due to in our study we are including cases with elective pregnancy terminations. CTDs besides NTDs increased slightly its prevalence in the period of time under study. Recent studies suggest that FA may influence the pathogenesis of CHDs through complex pathways, including epigenetic mechanisms that are responsible for transgenerational effects. A possible implication of epigenetic mechanisms is that a beneficial effect of FA in reducing the prevalence at birth of CHDs may take more than one generation to become fully apparent [12].

Others possible explanations of this increasing are the improved accuracy in the diagnosis and reporting of the less severe phenotypes by specialists included in the National Program for diagnosis, management and prevention of CHDs, the strength and long experience in the Cuban registries of BDs, the implementation of at least three prenatal transabdominal sonographic studies in all Cuban pregnant women in the primary health care and the evaluation of all pregnancies with any genetic risks in the secondary health care for the clinical geneticist, cardio pediatrics and high qualified sonographers in the Medical Genetics Centers in all Cuban provinces. Spatial epidemiology can give important clues when searching for putative environmental causes of a disease. Geospatial analysis has been used to examine the effects of the environmental factors on BDs and other adverse pregnancy outcomes [24,27]. A significant primary geospatial and temporal cluster for the folic acid- sensitive congenital defects under study was identified on the north-western municipalities of Corralillo and Quemado de Güines in the year 2017, where orofacial clefts and conotroncal heart defects were the most prevalent BDs.

The embryonic cardiac development is 3-7 weeks after conception and includes the time period when the mother likely recognizes her pregnancy, with subsequent initiation of FA supplementation. Most studies discovered that although many women take FA supplementation during pregnancy, a smaller percentage of women are taken FA supplementation during the critical cardiac developmental period because a few amount of women started preconceptually $[28,29]$. On the other hand, however, the possible protective effect of FA supplements on CHDs is controversial. While some studies have reported reduced risk of CHDs in children whose mothers have taken multivitamins or FA supplements, or after FA food fortification, other studies have reported no effect on CHDs of FA. For instance, in a study conducted in Norway, Leirgul et al. [30] found no risk reduction, even in the group with both FA and multivitamin supplements before and during pregnancy, suggesting the use of FA supplements does not prevent CHDs in the Norwegian population.

Secondary clusters of NTDs were identified at Placetas and Encrucijada, two municipalities where agricultural land areas predominated, mainly sugar cane plantations. Furthermore, in Placetas municipality there is a heavy concentration of aluminum foundries, most of them located unpropitiously inside house yards; in which process, air pollution (black smoke, fumes, soot, polycyclic aromatic hydrocarbons and other pollutants) and very elevated temperatures, are generated. A total of $153458 \mathrm{~m} 2$ of aluminum doors and windows were built here from 2013 to 2018 [9]. Literature has identified many factors related to the NTDs incidence, including hyperthermia, chemical elements in soil, exposure to pesticide and disinfectants, exposure to nitrate in drinking water, and geophysical condition. The category of 'pesticides' is usually taken to comprise insecticides, rodenticides, fungicides, herbicides and may even include nitrogen fertilizers; these represent a wide range of chemicals with different mechanisms of effect, although some are known to act as endocrine disruptors. Usually the proximity of the birth residence to crop spraying is taken as the exposure of interest $[13,24,31]$.

Non-occupational exposure to undesirable chemical substances may occur through the living environment of agricultural land areas or through residues in drinking water or foods. As an agricultural 
population, fertilizers and herbicides are frequently used by farmers in these municipalities, which might end up in soil or water bodies which subsequently increase nitrate or other chemical elements levels in drinking water. Likewise, more than one quarter (30.5\%) of inhabitants of these Villaclaran municipalities reside in rural areas, where drinking water is usually gotten from wells [9]. Since the mid-1920s, humans have doubled the natural rate at which nitrogen is deposited onto land through the production and application of nitrogen fertilizers (inorganic and manure). Nitrate levels in water resources have increased in many areas of the world largely due to applications of inorganic fertilizer and animal manure in agricultural areas. Studies conducted since the 1980 s of drinking water nitrate and central nervous system defects, found positive associations between higher drinking water nitrate exposure during pregnancy and NTDs or central nervous system defects combined [32].

A case control study of more than 300,000 infants in North Caroline, US, investigated maternal agricultural pesticide exposure based on application to crops within $500 \mathrm{~m}$ of maternal residence at birth. Among the more than 6000 infants with BDs, there was a significant association with the highest level of exposure [33]. Air pollution is emerging as relevant risk factor for BDs. A study, conducted among 212 men who attended infertility clinics for diagnostic purposes in Poland, identified that higher exposure to environmental particulate 10 micrometers or less in diameter (PM10) was associated with significant risk of disomy of chromosome 21; these results may hint that PM10 exerts a genotoxic action on germ cells as well as a teratogenic action [34]. Environmental pollution has also been associated to orofacial clefts. A recent study found spatial association of cases with this BDs and PM10 concentrations in the metropolitan area of Monterrey, Mexico [11].

Most BDs develops in the first trimester, therefore, exposures to environmental factors during the first weeks of pregnancy are most relevant for assessing risk factors for BDs [35]. Gastroschisis is a rare BDS where intestinal loops herniate through the fetal abdominal wall precisely in the first trimester of pregnancy. It's the most common abdominal wall malformation, but its etiology is still largely unknown. Multiple risk factors have been implicated in the development of gastroschisis, including maternal factors (young maternal age, low socioeconomic status), dietary factors (poor nutrition, low glutathione and beta-carotene, and high nitrosamine) and chemical exposures [36]. Gastroschisis shows the lowest prevalence rate in our study (6.7 per 10000 births); nevertheless, its frequency ( 1 per 1475 live births) is higher than the reported prevalence in the United States (1 per 2700) [37]. In a retrospective study of gastroschisis patients treated in Hawaii between 2008 and 2015 the birth rate was calculated to be 5.8 cases of gastroschisis per 10000 live births.
Most Hawaiian patients were from agricultural land use areas and restricted use pesticide application zone. The majority of these patients did not have the risk factors of maternal tobacco use, maternal alcohol use and maternal illicit drug use, suggesting that the exposure to pesticides could be related to this BDs [38]. Additionally, studies have reported clustering of gastroschisis by geography and time, suggesting that environmental factors such as infectious or toxic factors may underlie the etiologies of this BDs; for instance, Atrazine, a commonly used herbicide, and polycyclic aromatic hydrocarbons, which result from the incomplete combustion of organic matter, have been associated with gastroschisis too [36,37]. In a US agricultural area, the herbicide Atrazine was found in around 8\% of public water systems and its degradation product desethylatrazine was found in $10-12 \%$ of water samples [38].

In the current study a secondary spatial cluster of gastroschisis was found in Manicaragua; located at a the south-eastern of the Villa Clara province, it's a mountainous municipality where 59\% of its population lived in rural areas involved in agricultural land activities, mainly coffee and tobacco plantations. This geographical cluster could be due to environmental exposures, and further evaluation would be needed to assess this possibility, although the lack of statistical significance of clusters, indicated by Kulldorff's statistic, revealed the existence of clusters with an only slightly increased prevalence of these BDs. Another secondary spatiotemporal cluster in year 2013 was identified in the neighboring municipalities of Placetas and Remedios. San Juan de los Remedios was the eighth village founded in Cuba by Spanish founders in 1513; it's most important economic activities are tourism and agriculture, where the sugar canes production and its derivatives, as rum and alcohol, are predominant. Between 2013 and 2018 a total of 25048 hectoliters of alcoholic beverages were produced here [9].

Maternal alcohol consumption is associated with a variety of harmful effects to the fetus, as demonstrated by the range of impairments present in fetal alcohol spectrum. There are several possible mechanisms for an association between maternal alcohol intake and abnormal embryo-fetal development. Alcohol may impact development through its contribution to impaired conversion of retinol to retinoic acid, and cranial neural crest cells require retinoic acid for normal development and function [17]. Alcohol intake affects FA homeostasis by reducing folate absorption, thereby increasing folate excretion and causing inhibition of enzymes that are involved in FA metabolism and are essential for embryogenesis and early fetal development, such as methionine synthase and methylene tetrahydrofolate reductase $[17,39]$. Carmichael et al. [39] observed that the risk of CTDs in offspring was moderately elevated among women who consumed alcoholic beverages during the periconceptional period, and that risk was higher with increased frequency of drinking or increased number of drinks consumed per occasion. 
Might be possible that high availability of alcoholic beverages increase their consumption by pregnant women in this region? However, a role for alcohol may be confounded by other risk factors such as diet, deficiency in nutrition, smoking, or stress that can be associated with alcohol consumption in some contexts. BDs clusters frequently generate more concern and questions than certainties and answers. Although the identification of clusters does not provide a causal explanation for the geospatial clustering of specific health-related events, working hypotheses are often more easily generated and can be subsequently tested in future research efforts. More specific research, like case-control studies, can be conducted to further assess the causes of these clusters in Villa Clara province. The spatial pattern and clustering of folic acid- sensitive congenital defects provide important information for developing and refining geographical and population-specific prevention programs to reduce the BDs risk, and also could be a starting point in the identification of susceptibility genes associated with the occurrence of these BDs in these areas.

The strength of our study was the high quality of BDs registries with reliable prenatal and postnatal information and absence of unregistered community-based cases due to implemented through a community genetics network that currently has all municipal genetics services, enabled a virtually complete registration of both severe and minor BDs and which it's a complement of the hospital based registry. The limitation of this study is similar to all studies of spatial scan analysis that treat space as discrete; that is, territorial geopolitical units (municipalities) delimiting the analysis units, so the variable shape of study in space is conditioned by the size and form of the territorial unit of analysis.

\section{Conclusion}

Conotruncal congenital defects, Down syndrome and neural tube defects were the most frequent folic acid - sensitive congenital defects in the Cuban province of Villa Clara for the period 20132018. The temporal trends in the BDs under study showed a declining pattern. This study enabled the detection of primary and secondary spatial and spatio-temporal clusters of folic acid - sensitive BDs in the studied period, although precise reasons for these BDs clustering in these regions remain unknown. This cluster identification enables more focused research aimed at identification of specific factors involved in origin of these BDs. The findings presented in the study indicate areas in the Villa Clara province that should be prioritized for supporting public managers in the decision making process regarding this subject.

\section{Acknowledgement}

The authors thank all Genetic Counselors (Master's degree in genetic counseling) at the 13 municipalities of Villa Clara, who carry out the reevaluation of all newborns at month and three months after delivery in the primary health care for the community-based RECUMAC.

\section{Disclosures}

The authors are solely responsible for the design and conduct of this study; all study analyses, and the drafting and editing of the manuscript and its final contents.

\section{Funding}

This research received no external funding.

\section{Conflicts of Interest}

The authors declare no conflict of interest.

\section{References}

1. Groisman B, Juan Gili J, Giménez L, Poletta F, Bidondo MP, et al. (2017) Geographic clusters of congenital anomalies in Argentina. J Community Genet 8: 1-7.

2. Taboada LN (2016) Papel del ácido fólico, zinc y cobre en la prevención primaria de los defectos congénitos. Rev Cubana Med Gen Integ 35(4).

3. Taboada LN, Herrera MM, Algora HAE, Noche GG, Noa MMD (2016) Conglomerados espacio-temporales de defectos del tubo neural y niveles maternos de alfafetoproteína en Villa Clara (2011-2015). Rev CubanaObst y Ginecol 42(4).

4. Gatt M, Muscat BY, Lautier EC, Calleja N (2016) Folic Acid - prevention of birth defects. Malta Med J 28 (4): 49-54.

5. Hollis ND, Allen EG, Oliver TR, Tinker SW, Druschel C, et al. (2013) Preconception folic acid supplementation and risk for chromosome 21 nondisjunction: A report from the National Down Syndrome Project. Am J Med Genet Part A 161(3): 438-444.

6. Taboada LN (2019) Factores epigenéticos involucrados en el origen de defectos congénitos relacionados con la deficiencia materna de ácido fólico y otros micronutrientes. Acta Med Centro 13(3): 439-454.

7. Yang W, Carmichael SL, Shaw GM (2016) Folic Acid Fortification and Prevalences of Neural Tube Defects, Orofacial Clefts, and Gastroschisis in California, 1989 to 2010. Clinical and Molecular Teratology 106(12): 1032-1041.

8. Roblejo BH, Marcheco TB (2017) Genetics and genomic medicine in Cuba. Molecular Gen \& Genomic Med 5(3): 196-201.

9. (2018) Villa Clara Statistical Year Book. National Office of Statistic and Information. ONEI.

10. Kulldorff M (2018) SaTScan v9.6: software for the spatial and spacetime statistics.

11. Gasca SFM, Santos GJ, Elizondo DR, Mejia VGM, Ruiz PC, et al. (2019) Spatial clusters of children with cleft lip and palate and their association with polluted zones in the Monterrey Metropolitan Area. Int J Environ Res Public Health 16(14): 2488.

12. Liu S, Joseph KS, Luo W, León JA, Lisonkova S, et al. (2016) Effect of folic acid food fortification in Canada on congenital heart disease subtypes. Circulation 134(9): 647-655.

13. Liao Y, Wang J, Li X, Yaoqin Guo Y, Zheng X (2009) Identifying environmental risk factors for human neural tube defects before and after folic acid supplementation. BMC Public Health 9: 391.

14. Rosenthal J, Casas J, Taren D, Alverson CJ, Flores A, et al. (2013) Neural tube defects in Latin America and the impact of fortification: a literature review. Public Health Nutrition 17(3): 537-550. 
15. Kumar LD, Leem JH, Park M, Kim JA, Kim HC, et al. (2016) Increased prevalence of some birth defects in Korea, 2009-2010. BMC Pregn Childbirth 16: 61.

16. Cvjetkovic N, Maili L, Weymouth KS, Hashmi SS, Mulliken JB, et al. (2015) Regulatory variant in FZD6 gene contributes to nonsyndromic cleft lip and palate in an African-American family. Molecular Gen \& Genomic Med 3(5): 440-451.

17. Bezerra JF, Oliveira GHM, Soares CD, Cardoso ML, Ururahy MAG, et al. (2020) Genetic and non-genetic factors that increase the risk of nonsyndromic cleft lip and/or palate development. Oral Diseases 21(3): 393-399.

18. Taboada LN, Herrera MM (2018) Epigenetic mechanisms and Notch signalling pathway in the origin of different birth defects. Medicent Elect 22(3): 197-207.

19. James SJ, Pogribna M, Pogribny IP, Melnyk S, Hine RJ, et al. (1999) Abnormal folate metabolism and mutation in the methylenetetrahydrofolatereductase gene may be maternal risk factors for Down syndrome. Am J Clin Nutr 70(4): 495-501.

20. Taboada LN, Licea RA, Acosta CO, Pérez EO, Díaz SR, et al. (2011) Caracterización clínico genética del Síndrome Down en el Estado Plurinacional de Bolivia. Rev Cubana Genet Comunit 5(2-3): 82-88.

21. Díaz CS, Yokoyama RE, Del Castillo RV (2016) Genómica del síndrome de Down. Acta Pediatr Mex 37(5): 289-296.

22. Khoshnood B, Hermien De Walle ML, Arriola L, Addor MC (2015) Long term trends in prevalence of neural tube defects in Europe: population based study. BMJ 351: h5949.

23. Gedefaw A, Teklu S, Tadesse BT (2018) Magnitude of Neural Tube Defects and associated risk factors at three teaching Hospitals in Addis Ababa, Ethiopia. BioMed Res Int 2018: 4829023.

24. Li L, Wang J, Wu J (2012) A spatial model to predict the incidence of neuraltube defects. BMC Public Health 12: 951-961.

25. Taboada LN (2019) Advances in the knowledge of the molecular and cellular bases of congenital heart diseases. Second of two parts: Congenital heart defects CorSalud 11(4): 307-316.

26. Hobbs CA, Cleves MA, Mc Leod SL, Erickson SW, Tand X, et al. (2014) Conotruncal heart defects and common variants in maternal and fetal genes in folate, homocysteine, and transsulfuration pathways. Birth Defects Research (Part A) 100(2): 116-126.

27. Istvan M, Rouget F, Michineau L, Monfort C, Multigner L, et al. (2019) Landfills and preterm birth in the Guadeloupe archipelago (French West Indies): a spatial cluster analysis. Tropical Medicine and Health 47: 4 .

\section{ISSN: 2574-1241}

DOI: $10.26717 / B J S T R .2020 .29 .004865$

Noel Taboada Lugo. Biomed J Sci \& Tech Res

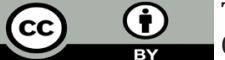

This work is licensed under Creative Commons Attribution 4.0 License

Submission Link: https://biomedres.us/submit-manuscript.php
28. Peyvandi S, Rychik J, Zhang X, Shea JA, Goldmuntz E (2015) Preconceptual folic acid use and recurrence risk counseling for congenital heart disease. Congenit Heart Dis 10(3): 219-225.

29. Taboada LN (2019) Avances en el conocimiento de las bases moleculares y celulares de las cardiopatías congénitas. Parte 1 de 2: Morfogénesis cardiaca. CorSalud 11(3): 233-240.

30. Leirgul E, Gildestad T, Nilsen RM, Fomina T, Brodwall K, et al. (2015) Periconceptional folic acid supplementation and infant risk of congenital heart defects in Norway 1999-2009. Paed and Perinatal Epidemiol 29(5): 391-400

31. Nicoll R (2018) Environmental contaminants and congenital heart defects: A Re-evaluation of the evidence. Int. J Environ Res Public Health 15(10): 2096.

32. Ward MH, Jones RR, Brender JD, De Kok TM, Weyer PJ, et al. (2018) Drinking water nitrate and human health: An updated review. Int. J. Environ. Res. Public Health 15(7): 1557.

33. Rappazzo KM, Warren JL, Meyer RE, Herring AH, Sanders AP, et al. (2016) Maternal residential exposure to agricultural pesticides and birth defects in a 2003 to 2005 North Carolina birth cohort Birth Defects Res. A Clin Mol Teratol 106(4): 240-249.

34. Jurewicz J, Radwan M, Sobala W, Polanska K, Radwan P, et al. (2015) The relationship between exposure to air pollutionand spermdisomy. Environmental Molecular Mutagen 56(1): 50-59.

35. Tinker SC, Gilboa S, Reefhuis J, Jenkins MM, Schaeffer M, et al. (2015) Challenges in studying modifiable risk factors for birth defects. Curr Epidemiol Rep 2(1): 23-30.

36. Yazdy MM, Werler MM, Feldkamp ML, Shaw GM, Mosley BS, et al. (2015) Spatial analysis of gastroschisis in the National Birth Defects Prevention Study. Birth Defects Research (Part A) 103(6): 544-553.

37. Souther C, Puapong DP, Woo R, Johnson SM (2017) Possible etiologies of increased incidence of gastroschisis. Pediatr Surg Int 33(11): 12091213.

38. Brender JD, Weyer PJ (2016) Agricultural compounds in water and birth defects. Curr Environ Health Rep 3(2): 144-152.

39. Carmichael SL, Shaw GM, Yang W, Lammer EJ (2003) Maternal periconceptional alcohol consumption and risk for conotruncalheart defects. Birth Defects Research (Part A) 67(10): 875-878.

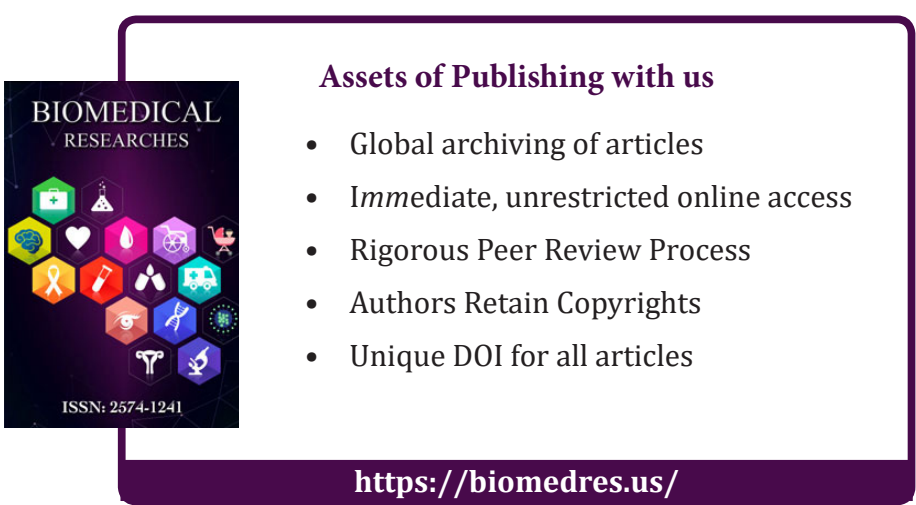

